\title{
Peromnes job evaluation method and its application to a library environment
}

\author{
R. Raju \\ E.G. Malherbe Library, University of Natal Libraries, Durban, P.O. Box 18091, Dalbridge, 4014 Republic of South Africa \\ Rajur@lib.und.ac.za
}

\begin{abstract}
The Peromnes job evaluation method is used extensively in all sectors of the South African economy, including tertiary educational institutions. The aim of this article is to examine the Peromnes job evaluation method as an evaluation method and to examine some of the problems with its application to a library environment.
\end{abstract}

Die Peromnes-taakevalueringsmetode word op groot skaal in alle sektore van die Suid-Afrikaanse ekonomie gebruik, tersiêre opvoedkundige inrigtings ingesluit. Die doel van hierdie artikel is om die Peromnes-taakevalueringsmetode as evaluasiemetode te ondersoek, asook sommige van die probleme wat ondervind word wanneer dit in 'n biblioteekopset toegepas word.

Job evaluation today is a well established personnel technique which first originated in the United States where it was developed during the 1930s and 1940s. One of the most important factors in determining wages or salaries is deciding how much one job is worth when compared with another job that is different in skill content, level of responsibility, working conditions, and such (Mulvie 1989: 86). Furthermore, no two jobs which are similar in content will be performed by individuals with the same level of competence, skills, attitude and level of motivation.

'In order to judge these differences in relation to a range of jobs, many organisations use job evaluation to determine how jobs may be placed in a hierarchy of their relative worth in order that employees may be paid fairly' (Mulvie 1989:8687).

It could therefore be said that job evaluation is a technique which seeks to promote the objective of 'fairness' by evaluating one job against another to establish their relative worth. However, it is not a scientific technique but a systematic comparison which aims to measure the skills and knowledge content of one job against another. It attempts to analyse the job, not the job holder. Job evaluation takes no account of the individual job holder's capabilities or personality.

There are four standard approaches to job evaluation which fall into two general categories, namely, nonquantitative and quantitative. The non-quantitative system is the simpler of the two approaches since it involves comparing whole jobs rather than specific factors within each job. The non-quantitative system uses simple ranking and grading, and relies on existing position grades or classification systems (Flippo 1984:292; Creth \& Duda 1989:81).

The quantitative system is a more detailed approach in which specific job factors are identified and then measured. All quantitative systems involve a formal breakdown of a job or position into specific factors that contribute to its value, or weight, and the assignment of certain finite values, usually numerical, to these factors. The two quantitative systems are the point system and the factor comparison system (Creth \& Duda 1989:81).

These four systems provide the basis for a large number and variety of job evaluation methods that are used in South Africa and other countries. In South African private and public sectors, the Paterson and Peromnes job evaluation methods are the ones most extensively used. There are other methods that are also used in South Africa. Some of the more popular methods used are: the Castellion method, the Questionnaire method of the National Institute for Personnel Research, the Hay MSL guide-chart profile method (which is extensively used in the United Kingdom) and the Urwick-Orr profile method. These methods are known internationally, some of which have originated abroad. Methods such as Peromnes, Castellion and the Questionnaire method of the National Institute for Personnel Research have been developed and tested in South Africa (Fact sheet 172 1988:1, Fact sheet 173 1988:1; Gerber, Nel \& Van Dyk 1993:460). It is therefore the aim of this article to examine the Peromnes job evaluation method as an evaluation method and to examine some of the problems with its application to a library environment.

\section{Peromnes job evaluation method}

The Peromnes job evaluation method has been used extensively over the past twenty years in all sectors of the South African economy including tertiary educational institutions. It is a locally developed job evaluation method which is the property of FSA Contact.

It is the view of FSA Contact that the Peromnes job evaluation method is suitable in its application to all jobs of any level in any type of organisation. This is so because the 
factors on which it is founded are represented to some degree of complexity in every job that there is. It is the establishment of the levels of complexity in each factor that, in aggregate, leads to the overall grade of complexity (or 'intrinsic value') of a job in relation to any other job. Jobs of equal grade, whatever their nature, are considered to be of approximately equal intrinsic value. It can be argued that, all things being equal, jobs of the same grade deserve roughly equal rates of remuneration (FSA Contact 1988:1).

\section{History of the Peromnes job evaluation method}

During the early 1960s, there was a need for systematic salary surveys. These surveys would serve both employers and employees as a means of comparing salaries in a 'scientific' way. The surveys would be of immense value to large organisations that had branches in all the provinces. With a systematic salary survey, employees would be able to compare salaries of colleagues in the other branches of the same organisation and with colleagues of other organisations. For such a 'scientific' comparison to take place, it was important to know what employees in the organisation and other organisations were doing. Therefore, it was imperative to have job descriptions and an evaluation system in place.

When South African Breweries (SAB) initiated systematic salary surveys in South Africa, they introduced job evaluation in their procedure to enable participating firms to equate their jobs with those covered by the survey. For this purpose, a simplified form of their Castellion job evaluation method was used. When their survey was eventually taken over by an independent company, the job evaluation method was retained and further developed in the course of time (Biesheuvel 1985:53-54).

In 1964 the SAB started the first systematic salary survey in South Africa. During the early period, the SAB began its survey with the limited objective of obtaining comparative data on the salaries for key jobs in companies in their group. This enquiry took the form of trading salary information on their jobs for similar information on corresponding jobs in companies deemed suitable in respect of size and industrial sector (Biesheuvel 1985;120).

The number of participating firms was initially too low to provide representative data. By March 1966, the report contained information from only 37 firms. In order to obtain wider job coverage and a more comprehensive national sample of participants, the selection of key posts had to be extended beyond those of primary interest to the SAB Group. This gave rise to the idea of compiling a chart, representing an imaginary company to serve as a model. It was named Peromnes Ltd (Biesheuvel 1985:120; Fact sheet 172 1988:2-3).

In summation, the Peromnes method of job evaluation was initially developed by $\mathrm{SAB}$ as a simplification of their Castellion method which was devised by Professor Simon Biesheuvel. The SAB survey was taken over by FSA
Contact (Pty) Ltd, a group of remuneration consultants, who are now solely responsible for marketing and supporting the Peromnes method in South Africa (Fact sheet 172 1988:2-3).

\section{Aims of the Peromnes job evaluation method}

FSA Contact furnishes three fundamental aims for the Peromnes job evaluation method. The primary aim is to determine the intrinsic worth of jobs based on systematic assessment of job content and requirements, independently of remuneration and without regard to the qualities and performance of the individuals who perform the jobs (FSA Contact 1990:2).

The secondary aims of the Peromnes job evaluation method are, firstly, to relate jobs to each other in terms of their evaluated worth and hence establish the relative complexity of jobs and create a rational structure within an organisation and; secondly, to provide a rational basis for remuneration within an organisation, so that appropriate rates of remuneration are assigned both to jobs themselves and to the individuals who perform these jobs (FSA Contact 1990:2).

\section{Peromnes factors}

The Peromnes method is a points scoring method of evaluating jobs. The method examines each job in terms of eight factors. These factors are the different aspects of the job worth. The factors are examined to cover the job's total content and requirements. Each of the factors will be represented to some degree in all jobs, although to a minimal degree in the case of the most unskilled work. The first six factors are concerned with job content. The last two factors are concerned with job requirements, that is, the basic expectations of an incumbent who will be able to perform the job competently. The eight factors are as follows:

- Problem solving: examines the quality and complexity of decision-making processes that are demanded in jobs;

- Consequences of error of judgement: probes the effects of adverse decisions on the activities, well-being and prestige of the organisation (or any of its parts), taking into account the controls and checks that may exist to prevent such errors or their recurrence;

- Pressure of work: scrutinises the level of stress inherent in a job;

- Knowledge: measures the level of knowledge required, in operational (not formal qualifications) terms, to perform the job competently;

- Job impact: rates the extent of influence that the job has on other activities, within and outside the organisation. When rating this factor, points are scored for both internal and external impact. The average of the two is the score that will be used; 
- Comprehension: evaluates the requirement of the job in undertaking written and spoken communications;

- Educational qualifications or intelligence level required in the post: measures the essential requirements that are considered, not merely desirable ones; and

- Subsequent training/experience: examines the period necessary to achieve competence in the job by the shortest possible reasonable route of advancement.

All eight factors denote inherent aspects or requirements of jobs. The peripheral matters such as physical working conditions, or supply and demand considerations are not included because they are considered to be very inconsistent. They may vary from place to place and from time to time.

\section{Evaluation process}

One of the strong points of the Peromnes method is that jobs are evaluated by committees. FSA Contact strongly recommends that organisations using the Peromnes method apply the principle of evaluating jobs using the committee system.

In the evaluation process, each job content factor is examined on a progressive scale (with identical points ranges) of complexity according to prescribed definitions. Each definition is numbered (1 to 9) at the top, and below it has a points range from 0 to 36 over the whole scale (see Figure 1). The objective in each case is to arrive at that definition which most satisfactorily describes the highest level of activity or the highest requirements of the jobs on the particular factor (Biesheuvel 1985:54-55, Fact sheet 172 1988:3; Mbatha 1984:22).

There is an appropriate range of points within each box which provides for differentiating degree to which the behaviour designated by the box applies. Each box has three points within it and two 'borderline' points, one at either end of the box. For example, box 2 has the points value 5, 6 and 7 within it, and 4 on its left border and 8 on its right border (see Figure 1). When evaluating, the committee must decide whether a definition within the box applies 'barely' (B), 'moderately' (M) or 'wholly' (W). This is referred to as the BMW principle. Where there is more than one sentence in a definition, the first sentence

\begin{tabular}{|r|r|r|r|r|r|r|r|c|}
\hline 1 & 2 & 3 & 4 & 5 & 6 & 7 & 8 & 9 \\
\hline & & & & & & & & \\
\hline 123 & 567 & $9 \ldots$ & & & & & $\ldots 31$ & 333435 \\
\hline$*$ & $*$ & $*$ & $*$ & $*$ & $*$ & $*$ & $*$ & $*$ \\
\hline
\end{tabular}

Note: the $*$ reflect the borderline score. For example, in Block one, the highest score is 3 and in Block two the lowest score is 5. The evaluator can give a borderline score of 4 .

Figure 1 Peromnes rating scale (definition blocks) must apply before subsequent statements can be considered (FSA Contact 1990:9).

When using the BMW principle, 'barely applicable' refers to between $5 \%$ and $20 \%$ of the key tasks in the job at the definition level indicated. With regard to "moderately applicable', the incumbent must perform more than $20 \%$ but less than $40 \%$ of the key tasks in the job at the definition level indicated. If the incumbent performs more than $40 \%$ of the key tasks involved in the job, it must be considered as 'wholly applicable'. However, if a definition applies 'wholly', the evaluation committee must examine the next definition to the right, that is, the next box. If the evaluation committee feels that the definitions in the next box does not apply to any considerable degree, but that there is a slight suggestion of its applicability, then a borderline score is used (FSA Contact 1990:9-10).

It is recommended by FSA Contact that any job which supervises or manages other jobs must always be credited with the scores of subordinate jobs in Problem solving, Consequences of error of judgement, and total Job impact. A subordinate job should never score the same as or higher than its immediate supervisor job in factors 1, 2, 5 internal, 5 overall, and 7 and 8 combined. If the two jobs are in the same discipline, this rule would also apply to factors 4 and 6. The examination of the factors in this way leads to a score on each of the first six factors. The total of the first six factors are added to the next two factors to give the total points value for the job (FSA Contact 1990:9-10; Wolfaardt 1985:8).

When evaluating a job, there is a method of checks and balances which the evaluating committee should use. For the great majority of jobs, the score on each of factors 1 to 6 should not deviate by more than four points on either side of the average score for those factors. Where this does happen, either the evaluation is suspect or the job is an unusual one. Another check is that the average of the score on factors 7 and 8 should not deviate by more than three points from the average of the scores on factors 1 to 6 (FSA Contact 1990:[2]).

The fact that the Peromnes system of job evaluation is such a popular system in South Africa is testimony to the advantages that it carries as an evaluation system. The evaluation method is being used extensively, as mentioned above, in tertiary institutions. However, there are problems with the system when applied to the library environment. This does not rule out the fact that there would be problems in its application to other areas of academic institutions or industry. The writer does not feel qualified to comment on the application of the job evaluation method to industry because of limited, first-hand experience in its application to industry. 


\section{Problems with the application of Peromnes to a library environment}

\section{'Definition organogram'}

When applying the Peromnes job rating scales, ${ }^{1}$ the Peromnes job evaluators need to have a global picture of the organisation and how the job description being evaluated contributes to the organisation. It is for this reason that the organisation needs to draw-up a 'definition organogram', that is, an organogram that defines the organisational structure and where in that hierarchy the library has its niche.

The 'definition organogram', in Appendix A, (given as an example to enhance discussion) is that of the University of Natal (Raju 1995:217). This organogram is typical of many large academic institution. The organogram highlights the lack of understanding of the structure of libraries. There are a number of sections (including the Library) which fall immediately under Academic Support (which is considered to be a sector). The examples given in the organogram compares departments such as Student Counselling and Audio-visual with the Library, as indicated in Appendix A. In Appendix A, the total employment population in Student Advisory Services is seven and the employment population in Audio-visual is three. The total staff population of the Library is eighty-six.

The definition of a sector in the Peromnes job rating scales states that there are

'Three possible connotations: (I) The whole of a functional division within an organisation (e.g. administration, finance, marketing, personnel, production); [(ii)] OR a significant part of an organisation in the geographic sense (e.g. a large factory, a large branch of a bank, or an area grouping of small branches); [(iii)] OR a small company which has insignificant influence on a whole business environment ...' (FSA contact 1990:[10]).

The job rating scale defines a section as '... comprising two or more different but associated systems of operations ...' and a systems of operations as

'A group of activities which are closely related, often involve several operators (though may involve only one), and may result in a team output or impact. Examples are a moderately-sized assembly line, a team of despatch personnel; a typing pool ... A system of operations would normally be controlled by a supervisor who is not considered to be at management level' (FSA contact 1990:[10]).

From the above definition, it would be inappropriate to classify a Branch Library as a systems of operations. The Branch Library has its own issue desk, Inter-library loans (ILL) and Reserved book room (RBR) sections; its own professional staff to catalogue and classify material and assist users with queries. Similarly, the Circulation Department in the Main Library has three systems of operations, Issue desk, Inter-library loans and Reserved book room.
According to the 'definition organogram', the Issue desk (which has four members of staff) is a systems of operations. However, no consideration is given to the fact that it is one of three systems of operations, which includes ILL (four members of staff) and RBR (six members of staff), in the Circulation Department. Furthermore, if the Issue desk at the Branch Library is a systems of operations, where does the rest of the functions at that Branch Library fall in this 'definition organogram'.

A more rational 'definition organogram' should, for the Library, read as shown in Figure 2.

This 'definition organogram' has a significant impact on the grading especially when allocating points for the Peromnes factors such as Job impact, Consequence of errors of judgement and Knowledge. Low scoring, as a result of the placement of the Library on the 'definition organogram', on these factors will result in a lower grade. It must be noted that in the definitions of sector, section and systems of operations, in the Peromnes job rating scales, the examples given are applicable predominantly to industry. It is the academic institution and its evaluators who decide how the examples given should be interpreted so that it could be applied to the organisation.

Any institution defining the library as a section will have the problem of 'low gradings'. However, if an institution defines their library as a sector, there is a strong possibility that the grades allocated will be higher than an institution defining the library as a section. This goes against the basic principle of applying a job evaluation system, that is renumeration equity for similar jobs.

\section{Definition of terms}

There are a number of simple terms within the definition blocks ${ }^{2}$ which would have an impact on the points score for a particular Peromnes factor. Terms such as often, significant, extensive and large number are some of the simple terms that dictate whether or not an incumbent would score in a particular definition block or not.

The Concise Oxford dictionary defines often as 'frequently, many times, at short intervals' (1987:707); significant as 'of considerable amount or effect or importance' (1987: 983); extensive as 'large; far-reaching, comprehensive' (1987:341); and large as 'of considerable or relatively great magnitude' (1987:565). All these terms are open to interpretation. The Peromnes job rating scales give definitions at the foot of each page for the first six factors, excluding

\begin{tabular}{|l|l|l|l|}
\hline Sector & \multicolumn{2}{|l|}{ Library } \\
\hline Section & Circulation & Subject librarian unit & $\begin{array}{l}\text { Branch } \\
\text { librarians }\end{array}$ \\
\hline $\begin{array}{l}\text { Systems of } \\
\text { operations }\end{array}$ & $\begin{array}{l}\text { Issue desk/ } \\
\text { RBR/ILL }\end{array}$ & $\begin{array}{l}\text { Subject librarians/ } \\
\text { Shelvers }\end{array}$ & \\
\hline
\end{tabular}

Figure 2 Definition organogram 
conclusive definitions of simple terms that could have farreaching results in terms of points score and resulting grades.

Peromnes takes for granted the interpretation of simple terms such as those mentioned above. This casts doubts on the objectivity and the standardisation of the method. Committees interpreting such terms liberally can score the incumbents at higher grades than a committee that is conservative in its interpretation.

\section{Pressure of work}

This factor assesses the pressure imposed on a job in terms of variety of tasks. In Peromnes, the functions of a reference librarian or subject librarian can be considered as routine because it is the performance of the same tasks repeatedly. However, no consideration is given to the differing complexity of the different queries and the switching from one academic discipline to another when dealing with information queries. Furthermore, no consideration is given, especially in larger libraries like the University library, to telephonic queries that the librarian has to attend to. It is assumed that there is no difference between a telephonic query and a query with the user present.

Although the activities are the same, the handling of a telephone query is very different to handling a query in the presence of the user. The method of handling the query is at two different levels.

When handling the query in the presence of the user, there is some sharing of information on a continuous basis. This ensures that at every wrong turn, there is guidance (question negotiation) on either side. However, with a telephone query, after the initial reference interview, interpretation of the query is the guiding factor. If the interpretation is incorrect, the end result will be 'incorrect'.

Therefore, despite the fact that the same activity is repeated on a continuous basis, the complexity and the level is variety enough to warrant consideration when evaluating the job description. Each question negotiation can vary from extremely complex, needing extensive professional knowledge, to straightforward.

In an interview with Dr. L.D. Naidoo from the University of Durban-Westville, it was stated that Pressure of work does not take into consideration volume. It is common knowledge among evaluators that the issue of volume of work is an institutional management issue. Dr. Naidoo believes that Peromnes should address specifically the issue of volume in its rating scale. The mere fact that the Peromnes job rating scales state that continual repetition of straightforward short-cycle tasks is not to be seen as pressurised work does not address the issue of volume. In Peromnes, volume means performing the same task repeatedly, for example, fixing bicycle handles in a production line. Dr. Naidoo gives the example of two lecturers to motivate for allocating points for volume: Lecturer $\mathrm{A}$ has ten second-year students to lecture and examine and, Lecturer B has four hundred to lecture and examine. Both

\begin{tabular}{|l|c|c|}
\hline Year & Durban & Pietermaritzburg \\
\hline 1988 & 32 & 10 \\
1989 & 34 & 10 \\
1990 & 35 & 10 \\
\hline \multicolumn{2}{|c|}{ (University of Natal calendar 1988, 1989, 1990)a } \\
\hline
\end{tabular}

Figure 3 Professional staff

lecturers have ten lecture periods per week. In such instances the question of volume must be a significant factor to consider.

Take for example the University of Natal, the number of professional librarians on the Durban campus, during the implementation stage of Peromnes (1988-1990), is reflected in Figure 3. This is inclusive of the University librarian. The same group (that is, the professional staff) in the Pietermaritzburg campus library, is also reflected in Figure 3.

The primary function of the University librarians is to manage the respective campus libraries. It would seem logical that the level of responsibility of the University librarian on the Durban campus will be higher than that of the University library on the Pietermaritzburg campus by virtue of the number of professional librarians that have to be managed. However, in Peromnes this volume is not taken into consideration. Both University librarians are on the same Peromnes grade.

\section{Problem solving}

Problem solving in the Peromnes job evaluation method is measured in terms of the 'clues' that are available and the nature of the 'alternatives'. In the library environment, the user requesting information is considered to be the 'clue'. The mere fact that the 'clue' is an unpredictable factor is in itself a problem to measure. This is exacerbated in an academic libráry environment. In an academic library, the librarian has to satisfy the request for in-depth, subjectspecific information. Such a query would entail intellectual, interdisciplinary (although it may be only two disciplines - for example, library science and history) interaction.

Furthermore, this intellectual interaction differs according to the level of the query. For example, when interacting with a first-year history student, there would be a fair amount of subject interaction and less library science; an in-depth subject-specific query from a professor in history will require extensive library science input, for example, choice of Dialog and CD-Rom files to be searched, the use of indexes and abstracts to locate journal material, and less history.

The reference interview, in any library environment, would require intellectual exchange in an attempt to ensure that users' requests are satisfied. The need for a good reference interview becomes more acute in an academic 
library because the request is for detailed, subject-specific information. The reference tools are complicated and are of a variety. Therefore, to satisfy the request for information, there is a high demand for intellectual exchange that would result in satisfied users.

When evaluating library posts, the intellectual interaction mentioned above, must be adequately and explicitly compensated for in the problem-solving factor of the job evaluation method. However, this is seriously lacking in the Peromnes method of job evaluation.

\section{Educational qualifications}

Educational qualifications, as a Peromnes factor, is assessed on the minimum essential qualifications that are normally required for a person before acceptance to the job. When scoring in this factor, credit is given for vertical educational qualifications. The assumption is that there is no need for a second or third horizontal qualification.

It is generally accepted that to become a professional librarian, the minimum educational qualifications is a professional four-year bachelor's degree in Library Science or equivalent. However, to become the University librarian, the incumbent may need another vertical educational qualification with a substantial number of years of experience, or another relevant horizontal educational qualification, for example, a Masters in Business Administration (a management qualification). At this level of management, there is a need for formal management qualifications. If the incumbent does have the additional management qualifications, Peromnes does not have the facility to credit the incumbent.

It has been argued that that which has been gained in terms of points score for factor seven will be lost in factor eight and vice versa. However, there is a point where experience cannot substitute for educational qualifications. By the same token, there is a cut-off point where educational qualifications can substitute for experience. In Peromnes there are no guidelines as to the limits or ceiling for substitution.

\section{Professional status of librarians}

Raju (1995:167-168) states that

'... librarians could not be scored in particular blocks for the different factors (for example, block six of factor four) because they were not considered as professional. In an E-Mail message to the writer ..., the chairperson of [an] evaluation committee outlined why librarians were not considered as professionals. It was stated that, "... there are many interpretations of the word 'professional' but because Librarians are classified by SAPSE as SUPPORT professionals and because there is no legislation requiring membership of a professional body (e.g. SA Medical and Dental Council) we could not, for evaluation purposes, regard Librarian posts in the same category as

Doctors, Lawyers, Engineers etc. ...”' .

If the above is true, then it must be argued that the University librarian of the University of Natal would not be considered as a professional. Therefore, in terms of the scoring process, the University librarian should also not get into the above-mentioned blocks. The mere fact that the University librarian is on a higher Peromnes grade than the other librarians indicates that the evaluation committee was satisfied that the definitions in the above-mentioned block were applicable to the incumbent and went on to score the incumbent in a higher scoring block.

\section{Conclusions}

The Peromnes job evaluation method is a technique which seeks to promote the objective of 'fairness' by evaluating one job against another to establish their relative worth. However, like all other job evaluation methods, it is not a scientific technique but a systematic one which aims to measure the skills and knowledge content of one job against another.

Despite the fact that the method is used extensively in South Africa including tertiary institutions, there are problems with its application to the library environment. Some of the problems identified were, firstly, the classification of a library as a section in the 'definition organogram'. Classifying a library as a section would impact negatively on the final gradings. Secondly, Peromnes takes for granted the interpretation of simple terms such as often, significant, extensive and large number. This casts doubts on the objectivity and the standardisation of the method. Thirdly, there are problems with the capacity of the Peromnes factors to measure library functions and responsibilities. Fourthly, the use of minimum educational qualifications in the Peromnes method is unsatisfactory. And lastly, there is a problem with librarians not being considered as professionals when applying the Peromnes factors.

\section{Notes}

1. Peromnes job rating scales is the tool used by the grading committees to grade the job description.

2. Definition blocks see - 'The evaluation process' including Figure 1.

\section{References}

Biesheuvel, S. 1985. Work motivation and compensation: volume 2: compensation procedures. New York: McGraw-Hill.

The Concise Oxford dictionary. 1987. Oxford: O.U.P.

Creth, S. \&Duda, F. 1989. Personnel administration in libraries. 6th ed. London: Neal-Schuman.

Fact sheet 172: job evaluation continued. 1988. IPM journal, July: $1-4$.

Fact sheet 173: job evaluation continued. 1988. IPM journal, August: 1-4. 
Flippo, E.B. 1984. Personnel management. 6th ed. Auckland: McGraw-Hill.

FSA Contact. 1988. The Peromnes job evaluation system. [Unpublished notes].

FSA Contact (Pty) Ltd. 1990. Peromnes job rating scales. [Unpublished Peromnes job rating scales].

FSA Contact. 1990. Peromnes: notes on Peromnes job evaluation system. Johannesburg: FSA Contact (Pty) Limited.

Gerber, P.D., Nel, P.S. \& Van Dyk, P.S. 1993. Human resources management. 2nd ed. Halfway House: Southern Books.

Mbatha, D. 1984. Job evaluation. Braamfontein: Institute for Industrial Relations.
Mulvie, A. 1989. Wage and salary administration. In Molander, C. (ed.) Human resource management. pp. 77-95. Kent: Chartwell-Bratt.

Raju, R. 1995. A case study of the application of the Peromnes method of job evaluation to the University of Natal, Durban Libraries. MIS thesis. Pietermaritzburg: University of Natal.

University of Natal. 1988. University of Natal calendar. University of Natal. 1989. University of Natal calendar. University of Natal. 1990. University of Natal calendar.

Wolfaardt, P. 1985. Die Peromnes posevalueringstelsel as diagnostiese hulpmiddel vir 'n organisasie ontwikkelingsprogram. IPM journal, 4(6):6,8,10,12.

\section{Appendix A}

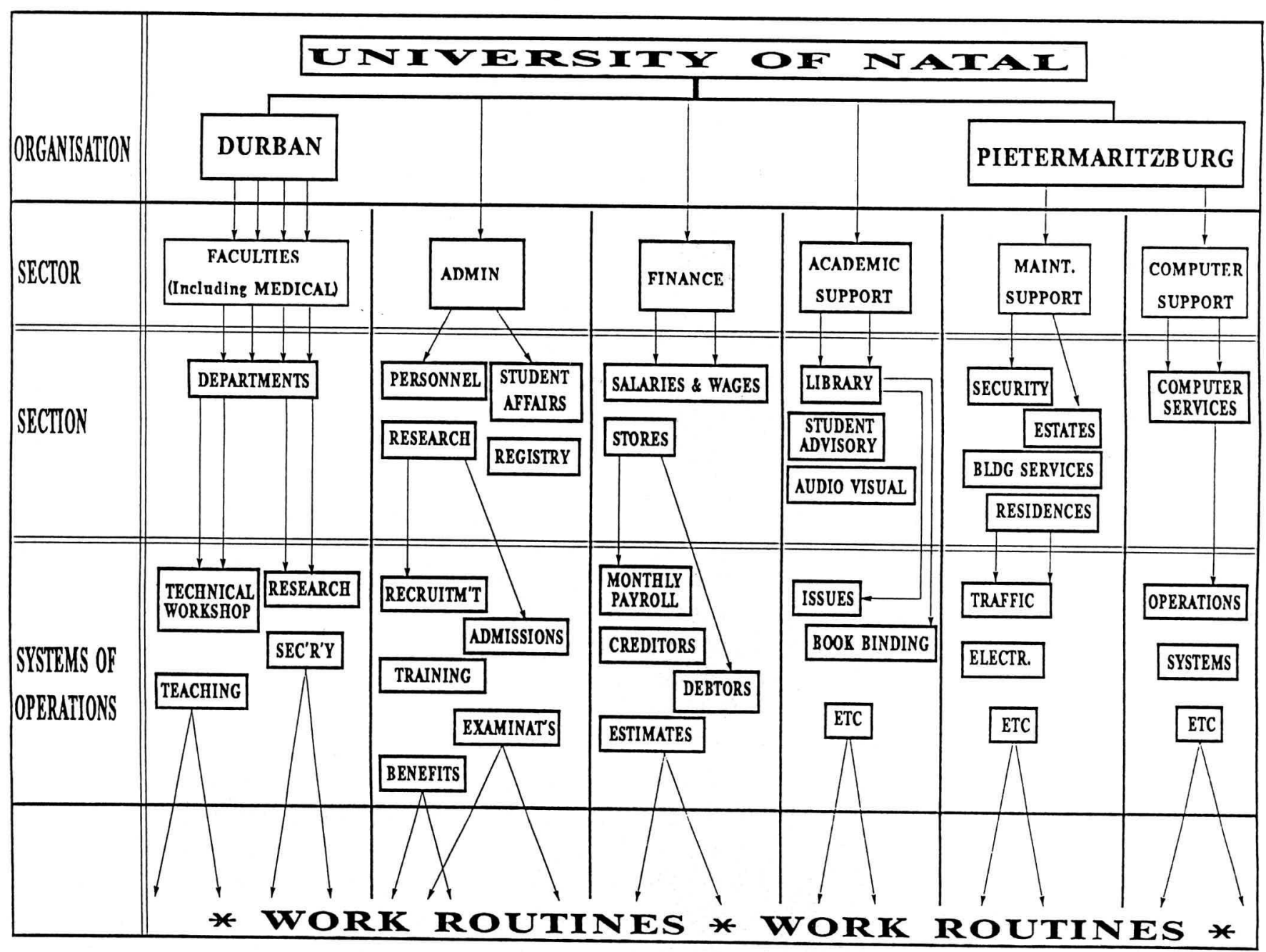

